\title{
Decreased Proteasomal Function Induces Neuronal Loss and Memory Impairment
}

Utano Tomaru, ${ }^{*}$ Tomoki Ito, ${ }^{*}$ Yu Ohmura, ${ }^{\dagger}$ Kei Higashikawa, ${ }^{\ddagger}$ Syota Miyajima, ${ }^{*}$ Ruka Tomatsu, ${ }^{*}$ Tsunehito Higashi, ${ }^{\S}$ Akihiro Ishizu, ${ }^{\top}$ Yuji Kuge, ${ }^{\ddagger}$ Mitsuhiro Yoshioka, ${ }^{\dagger}$ and Masanori Kasahara*

From the Departments of Pathology, ${ }^{*}$ Neuropharmacology, ${ }^{\dagger}$ and Cellular Pharmacology, ${ }^{\S}$ Faculty of Medicine and Graduate School of Medicine, the Central Institute of Isotope Science, ${ }^{\ddagger}$ and the Department of Medical Laboratory Science, ${ }^{\boldsymbol{T}}$ Faculty of Health Sciences, Hokkaido University, Sapporo, Japan

Accepted for publication October 6, 2020.

Address correspondence to Utano Tomaru, M.D., Ph.D., Department of Pathology, Faculty of Medicine and Graduate School of Medicine, Hokkaido University, Kita-15 Nishi-7 Kita-ku, Sapporo 060-8638, Japan. E-mail: tomaruu@med. hokudai.ac.jp.

\begin{abstract}
Alzheimer disease (AD) is a progressive neurodegenerative disorder and the most common type of dementia worldwide. There is considerable evidence of age-related disruption of proteostasis being responsible for the development of $A D$. The proteasome is a multicatalytic enzyme complex that degrades both normal and damaged proteins, and an age-related decline in its activity has been implicated in age-related pathologies. Although proteasomal dysfunction is assumed to be a key $A D$ hallmark, it remains unclear whether its role in disease onset is causative or secondary. In this study, we demonstrate that mice with proteasomal dysfunction exhibited memory impairment with associated neuronal loss, accumulation of phosphorylated tau, and activation of endoplasmic reticulum (ER) stress -related apoptosis pathways. Impaired proteasomal activity also activated ER stress-related apoptosis pathways in HT-22, a murine hippocampal neuronal cell line. HT-22 cell death, caused by proteasomal inhibition, was prevented by an inhibitor of c-Jun N-terminal kinase, an ER stress-related molecule. Collective evidence suggests that impaired proteasomal activity alters proteostasis, and subsequent ER stress-mediated pathways play pivotal roles in neuronal loss. Because aging decreases proteasomal function, age-related impairment of proteasomes may be involved in the development and progression of $A D$ in elderly patients. (Am J Pathol 2021, 191: 144-156; https://doi.org/10.1016/ j.ajpath.2020.10.004)
\end{abstract}

Abnormalities in the maintenance of proteostasis are considered to be a common feature in various neurodegenerative diseases, such as Parkinson disease and Alzheimer disease $(A D)$. In these conditions, the accumulation and aggregation of abnormal proteins in the brain cause altered synaptic function and eventual neuronal loss. ${ }^{1} \mathrm{AD}$ is a progressive neurodegenerative disease characterized by synaptic dysfunction and accumulation of abnormal aggregates formed by $\beta$-amyloid $(A \beta)$ or phosphorylated tau ( $p$ tau) proteins. Aging is associated with a gradual decay of the buffering capacity of the proteostasis network, the main risk factor for developing $\mathrm{AD} .^{2}$

To maintain proteostasis, several cellular compartments and protein degradation systems cooperate. The endoplasmic reticulum (ER) is a cellular compartment involved in protein folding and secretion. Misfolded ER proteins are retrotranslocated across the ER membrane into the cytosol and are degraded by the proteasome, a process called
ER-associated degradation. ${ }^{3}$ However, an increase in unfolded proteins causes ER stress, resulting in the activation of the unfolded protein response, a signal transduction pathway that stimulates adaptive programs to recover homeostasis or trigger apoptosis of irreversibly damaged cells. ${ }^{4}$ Recent studies have revealed that ER stress plays a key role in neurodegeneration. ${ }^{5}$ The ubiquitin-proteasome system is a major protein degradation pathway that is responsible for the degradation of functional, damaged, or misfolded proteins. ${ }^{6,7}$ However, proteasomal activity decreases with age. ${ }^{8-10}$ Because the proteasome plays an essential role in cellular homeostasis, an age-associated decline in proteasome function is assumed to contribute to

Supported in part by Japan Society for the Promotion of Science Grantin-Aid for Scientific Research 18H02629 (U.T.); and Smoking Research Foundation grant 2018 G008 (U.T.).

Disclosures: None declared. 
the development of age-related pathologies and to the aging process itself. $^{11}$ Indeed, recent evidence indicates that reduced 26S proteasome assembly shortens life span and enhances neurodegeneration in Drosophila. ${ }^{9}$ Impaired proteasome function has been implicated in the pathogenesis of many neurodegenerative diseases, as either a primary cause or a secondary consequence. ${ }^{12-14}$

Previously, we established a transgenic (Tg) mouse model with decreased proteasomal chymotrypsin-like activity. ${ }^{15} \mathrm{Tg}$ mice exhibited shortened lifespans and agerelated phenotypes with the accumulation of polyubiquitinated and oxidized proteins. These mice showed retinal degeneration and were susceptible to age-related disorders, such as high-fat diet-induced hepatic steatosis and cigarette smoke-induced pulmonary emphysema. ${ }^{15-17}$ In the present study, using this model, we provide in vivo evidence that decreased proteasomal function causes memory impairment with neuronal loss. The brain tissue of $\mathrm{Tg}$ mice demonstrated activation of ER stress-mediated apoptosis pathways, as well as an increase in p-tau, with accumulation in the neuronal cells of the hippocampus. We also provide in vitro evidence that impaired proteasomes cause ER stress and cell death in HT-22, a murine hippocampal neuronal cell line. These data suggest that proteasome dysfunction is involved in memory impairment as a result of ER stress and hyperphosphorylation of tau, which may together constitute a common mechanism in the pathogenesis of age-related neurodegenerative diseases.

\section{Materials and Methods}

\section{Mice and Behavioral Experiments}

$\mathrm{Tg}$ mice expressing $\beta 5 \mathrm{t}$ were established as previously described. ${ }^{15}$ C57BL/6 mice were used as wild-type (WT) controls. Experiments were performed using 4- to 24-week-old mice. Mice were housed under a 12-hour light-dark cycle in climate-controlled, pathogen-free barrier facilities. Behavioral experiments used 24-week-old WT and Tg mice. An open field test was performed using a novel cage $\left(30 \times 30 \times 30-\mathrm{cm}^{3}\right.$ acrylic box $)$ to evaluate locomotor activity. The illumination of the room was set to $20 \mathrm{~lx}$. The total travel distance and the total number of crosses across $5 \times 5-\mathrm{cm}$ squares were monitored for 30 minutes. An elevated plus-maze test was performed to evaluate locomotor activity and anxiety-like behavior, as described previously. ${ }^{18}$ The total distance traveled in the maze and the time spent in the open arms were monitored for 10 minutes. The behavior of each mouse was captured by a charge-coupled device camera and automatically analyzed using LimeLight software version 2 (Actimetrics, Wilmette, IL). To test the pain response, mice were placed on a $54.5^{\circ} \mathrm{C}$ hot plate, and the latency before animals licked their hind paws or jumped was measured (hot-plate test). The cutoff time for the hot-plate test was set at 30 seconds. For the contextual fear conditioning test, each mouse was acclimated in a foot-shock box $(30.5 \times 24.1 \times 21.0 \mathrm{~cm}$; Med Associates, Inc., Fairfax, VT) for 5 minutes. After placing a mouse in the box, 5 -second foot shocks (shock intensity, $0.5 \mathrm{~mA}$ ) were administered 10 times at 25 -second intervals. After the last foot shock, the mouse was returned to its home cage. At 24 and 48 hours later, each mouse was placed in the foot-shock box but without being shocked. Freezing behavior, consisting of a lack of movement (except for respiration), an arched back, and retraction of the ears, was monitored for 10 minutes to analyze fear memory retrieval. The appropriate number of samples was defined on the basis of the nature of each experiment. All animal experiments were performed at Hokkaido University Graduate School of Medicine according to the NIH's Guide for the Care and Use of Laboratory Animals. ${ }^{19}$

\section{Western Blot Analysis}

Tissues or cells were lysed in a buffer containing $150 \mathrm{mmol} /$ $\mathrm{L} \mathrm{NaCl}, 20 \mathrm{mmol} / \mathrm{L}$ Tris-HCl (pH 7.5), 0.2\% NP-40, and 1 $\mathrm{mmol} / \mathrm{L}$ dithiothreitol, and then centrifuged at $15,000 \times g$ for 10 minutes. The supernatants $(20-\mu \mathrm{g}$ aliquots of total proteins) were subjected to SDS-PAGE and blotted onto nitrocellulose membranes. The blots were probed with antibodies and reacted with horseradish peroxidase-conjugated antirabbit or goat IgG (Jackson ImmunoResearch, West Grove, PA) for immunodetection. The immune complexes were visualized by enhanced chemiluminescence and analyzed by Amersham Imager 680 (Amersham, Piscataway, NJ). Antibodies for the proteasomal subunits $\beta 5 \mathrm{t}, \beta 5 \mathrm{i}, \beta 5$, and $\beta 6$ were purchased from MBL (Nagoya, Japan), Enzo Life Sciences (Plymouth Meeting, PA), Santa Cruz Biotechnology (Dallas, TX), and Abcam (Cambridge, UK), respectively. Antibodies for C/EBP homologous protein and c-Jun N-terminal kinase (JNK) were purchased from Santa Cruz Biotechnology. Antibodies against phosphorylated JNK, tau, p-tau (Ser396; PHF13), glycogen synthase kinase $3 \beta$ (GSK-3 $\beta$ ), phosphorylated GSK-3 $\beta$, cyclin-dependent kinase 5 (CDK5), p35/p25, and protein kinase-like endoplasmic reticulum kinase were purchased from Cell Signaling Technology (Danvers, MA). All antibodies were used according to the manufacturers' recommendations. All information, including the dilution and organism, is available on data sheets from the relevant companies. For immunoblotting using purified proteasomes, proteasomes were enriched using the CycLex Proteasome Enrichment \& Activity Assay Kit (MBL). Tissue lysates (2 $\mathrm{mg}$ of protein) were incubated with control resin or ubiquitinlike domain resin, and then subjected to immunodetection according to the manufacturer's instructions.

\section{Proteasomal Activity}

Proteasomes were enriched from brain tissue using the CycLex Proteasome Enrichment \& Activity Assay Kit. Brain tissue lysates (1 $\mathrm{mg}$ of protein) were incubated with control or ubiquitin-like domain resin, and applied to a 
proteasomal chymotrypsin-like activity assay according to the manufacturer's instructions. All data were corrected by the purified proteasomal amount and expressed as relative fluorescence units per $1 \mathrm{mg}$ protein. For analysis of the proteasomal activity in HT-22 cells, proteasome activity assay kits (Proteasome-Glo Cell-Based Assay; Promega, Madison, WI) were used according to the manufacturer's instructions. Briefly, cells were incubated with specific luminogenic proteasome substrates (Suc-LLVY-aminoluciferin for chymotrypsin-like activity; Promega), and substrate luminescence was measured by a luminometer. The number of viable cells in each well was measured by ATP measurement methods using luciferase reactions (CellTiter-Glo Luminescent Cell Viability Assay; Promega). Data were corrected for the number of viable cells and expressed as the ratio of substrate luminescence/ATP luminescence. All measurements were performed in triplicate.

\section{Protein Analysis}

Brain tissues were lysed in a buffer containing $150 \mathrm{mmol} / \mathrm{L}$ $\mathrm{NaCl}, 20 \mathrm{mmol} / \mathrm{L}$ Tris- $\mathrm{HCl}(\mathrm{pH} 7.5), 0.2 \% \mathrm{NP}-40$, and 1 $\mathrm{mmol} / \mathrm{L}$ dithiothreitol, and centrifuged at $15,000 \times g$ for 10 minutes. The levels of polyubiquitinated proteins, nerve growth factor (NGF), and $A \beta$ were quantified by enzymelinked immunosorbent assay. Detection kits for polyubiquitinated proteins, NGF, and $\mathrm{A} \beta$ were provided by CycLex (Nagano, Japan), Sigma-Aldrich (St. Louis, MO), and Wako (Osaka, Japan), respectively.

\section{Quantitative RT-PCR}

Total RNA from brain tissue was isolated using an ISOGEN II kit (NIPPON GENE, Tokyo, Japan), then treated with DNase I (Invitrogen, Waltham, MA) and converted to cDNA with a GoTag 2-Step RT-qPCR System (Promega). Quantitative PCR was performed in triplicate using $75 \mathrm{ng}$ cDNA, and the expression of $N G F-\beta$ was analyzed by a Thermal Cycler Dice (Takara Bio, Inc., Shiga, Japan). Cycling conditions were 1 cycle at $95^{\circ} \mathrm{C}$ for 2 minutes, followed by 40 cycles of denaturation at $95^{\circ} \mathrm{C}$ for 15 seconds, annealing at $60^{\circ} \mathrm{C}$ for 30 seconds, and extension at $72^{\circ} \mathrm{C}$ for 30 seconds. The primer sequences were $5^{\prime}$-CAAGGACGCAGCTTTCTATACTG-3' (forward) and $5^{\prime}$-CTT-CAGGGACAGAGTCTCCTTCT- $3^{\prime}$ (reverse) for $N G F-\beta$ and $5^{\prime}$-CT-TCCCCAACAGTGCCAA-3' (forward) and $5^{\prime}$-ACTTTCAGTCAGCCCCTTTG-3' (reverse) for $18 S$ rRNA.

\section{Autoradiography Study}

Brain tissues were embedded in OCT compound (Sakura Finetek Japan Co, Ltd, Tokyo, Japan) and frozen in isopentane/dry ice. Frozen sections $(10 \mu \mathrm{m}$ thick) were washed with phosphate-buffered saline without calcium or magnesium and preincubated with $10 \mathrm{mg} / \mathrm{mL}$ sodium $\mathrm{L}^{-}$ ascorbate in saline at room temperature. The sections were then incubated with approximately $100 \mathrm{kBq}$ of $\left[{ }^{125} \mathrm{I}\right]$ iomazenil (carrier free; generously provided by Nihon MediPhysics Co, Tokyo, Japan) for 60 minutes at room temperature. After washing and drying, the sections were exposed to a phosphor imaging plate (Fuji Photo Film Co, Ltd, Tokyo, Japan). After the exposure, the imaging plate was scanned with an FLA 7000 Bio-Imaging Analyzer (Fuji Photo Film Co, Ltd) and analyzed using Multi Gauge V3.0 (Fuji Photo Film Co, Ltd). To verify the specific binding of $\left[{ }^{125} \mathrm{I}\right]$ iomazenil, sections were preincubated with $10 \mathrm{mmol} / \mathrm{L}$ clonazepam in $10 \mathrm{mg} / \mathrm{mL}$ sodium L-ascorbate with saline. Data were evaluated in terms of relative values, with the mean intensity of WT controls set at 1 .

\section{Histologic and Immunohistochemical Analysis}

Formalin-fixed brain tissues were embedded in paraffin, and sections $(6-\mu \mathrm{m}$ thick) were stained with hematoxylin and eosin. Histologic images of five randomly selected fields in the hippocampal CA1 region were captured, and numbers of neuronal cells in squares of $500 \times 500 \mu \mathrm{m}$ were counted by three different experimenters (U.T., T.I., and A.I.), all of whom were blinded to group allocation. For immunohistochemistry, tissue slides were processed for antigen retrieval by a standard microwave-heating technique, then incubated with antibodies and detected with streptavidin-biotin-horseradish peroxidase. Antibodies against ubiquitin, $\mathrm{p}$-tau, and $\mathrm{A} \beta$ were purchased from Dako (Tokyo, Japan), Abcam, and Cell Signaling Technology, respectively. Apoptotic cells in brain tissues were detected by the terminal deoxynucleotidyl transferasemediated dUTP nick-end labeling method with an In Situ Apoptosis Detection Kit (Takara Bio, Inc.) according to the manufacturer's instructions.

\section{Cell Culture and Detection of Cell Death}

HT-22 is a murine hippocampal neuronal cell line. HT-22 cells, which were kindly provided by Dr. David Schubert (Salk Institute, La Jolla, CA), were grown in Dulbecco's modified Eagle's medium supplemented with $20 \%$ fetal bovine serum, $100 \mathrm{U} / \mathrm{mL}$ penicillin, and $100 \mathrm{U} / \mathrm{mL}$ streptomycin in an atmosphere of $5 \% \mathrm{CO}_{2}$ and $95 \% \mathrm{O}_{2}$ at $37^{\circ} \mathrm{C}$. Equivalent numbers (1.0 to $\left.5.0 \times 10^{5}\right)$ of HT-22 cells were plated and treated with MG-132 (12.5 to $50.0 \mu \mathrm{mol} / \mathrm{L})$ containing Dulbecco's modified Eagle's medium with supplements for 24 hours. For treatment with the JNK inhibitor SP600125 or cigarette smoke extract (CSE), cells were incubated with MG-132 and $100 \mathrm{nmol} / \mathrm{L}$ SP600125 or 3.5\% CSE for 24 hours. CSE was prepared as previously described. ${ }^{17,20}$ For non-treated controls, phosphate-buffered saline and normal medium were used. The number of viable cells in each well was measured by ATP measurement methods using luciferase reactions (CellTiter-Glo 
Luminescent Cell Viability Assay; Promega). All measurements were performed in triplicate.

\section{Image Analysis}

Western blot data were subjected to image analysis using ImageJ software version 1.53e (NIH, Bethesda, MD; https:// imagej.nih.gov/ij).

\section{Statistical Analysis}

We performed statistical analyses of two unmatched groups using the unpaired two-tailed $t$-test. For analysis of three or more unmatched groups, we used one-way analysis of variance with multiple comparisons/post-hoc tests. $P<0.05$ was considered significant.

\section{Results}

\section{Decreased Proteasomal Function Causes Memory Impairment in Vivo}

We previously generated $\mathrm{Tg}$ mice with decreased proteasomal chymotrypsin-like activity by introducing mouse $\beta 5 \mathrm{t}$ as a transgene. ${ }^{15} \beta 5 \mathrm{t}$ is one of the $\beta 5$-family subunits, and has only weak chymotrypsin-like activity. ${ }^{21} \mathrm{Tg}$ mice were smaller in size than WT mice, but displayed no apparent histologic abnormalities before 12 weeks of age. After 24 weeks of age, $\mathrm{Tg}$ mice gradually became weak and died without any gross pathologic changes. ${ }^{15}$ In brain tissues, $\beta 5 \mathrm{t}$ was detected in $\mathrm{Tg}$ mice, while endogenous levels of $\beta 5$ were decreased (Figure 1A). Immunoblotting using purified proteasomes showed that $\beta 5 \mathrm{t}$ was incorporated into $20 \mathrm{~S}$ proteasomes in brain tissues of $\mathrm{Tg}$ mice (Supplemental Figure S1). $\quad \beta 5$-containing $20 \mathrm{~S}$ proteasomes were decreased in the brains of $\mathrm{Tg}$ mice, indicating that the transduced $\beta 5 \mathrm{t}$ was preferentially incorporated into $20 \mathrm{~S}$ proteasomes over $\beta 5$. In addition, the brain tissues of $\mathrm{Tg}$ mice demonstrated decreased proteasomal chymotrypsinlike activity and increased polyubiquitinated proteins compared with WT mice (Figure 1, A-C). Immunohistochemical analysis of $\mathrm{Tg}$ mice showed accumulation of ubiquitin in both the nucleus and cytoplasm of neuronal cells, but no neurofibrillary tangles (NFTs) or inclusion-like structures commonly seen in neurodegenerative diseases (Figure 1D).

We then examined whether $\mathrm{Tg}$ mice showed any behavioral abnormalities related to the neurologic findings. There were no differences between WT and Tg mice in the total distance traveled or the total number of grids crossed in the locomotor activity test in an open field (Figure 2A). In the elevated plus-maze test, the total distance traveled and
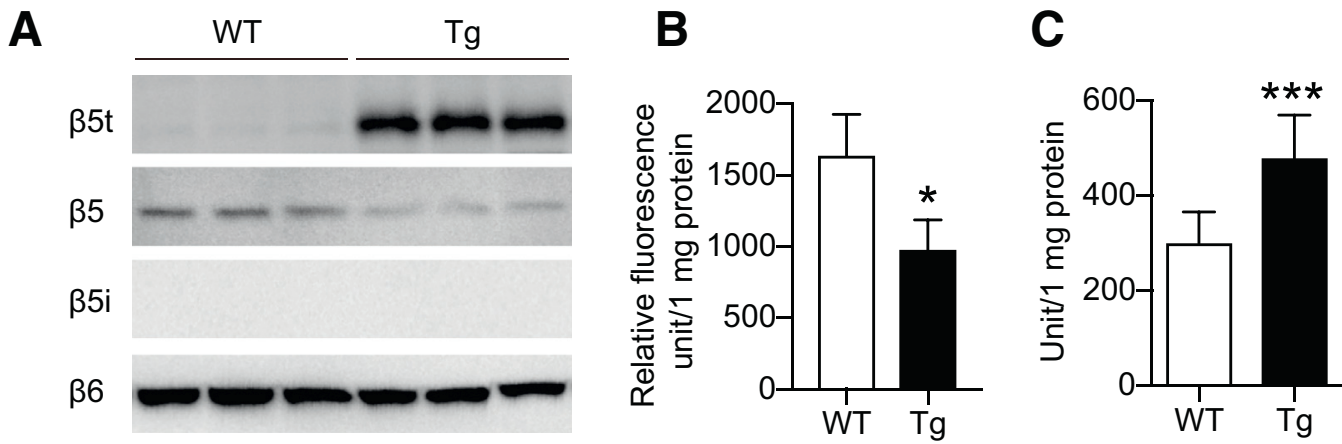

D

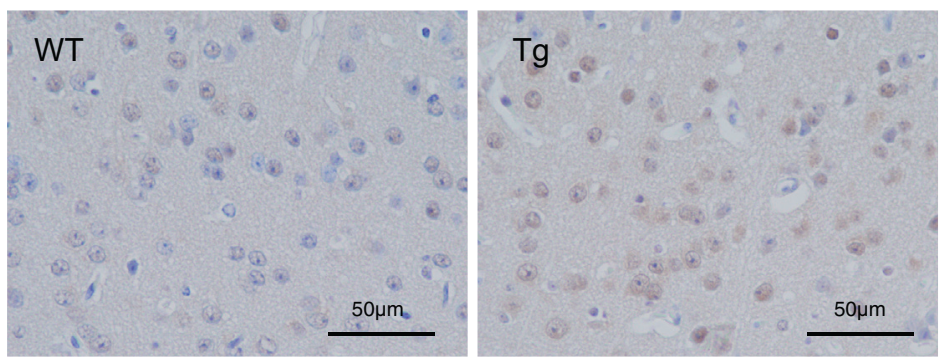

Figure 1 Brain tissue with decreased proteasomal activity exhibits accumulation of polyubiquitinated proteins in vivo. A: Expression of $\beta 5 t$ in the brain tissue of wild-type (WT) and transgenic (Tg) mice. Brain tissue extracts were immunoblotted with $\beta 5 \mathrm{t}, \beta 5$, $\beta 5 \mathrm{i}$, and $\beta 6$ antibodies. $\beta 5 \mathrm{t}$ was detected only in Tg mice, and endogenous $\beta 5$ was decreased. Lanes 1,2, and 3 represent individual mice. B: Proteasomal activity in the brains of Tg mice. Proteasomes were purified by ubiquitin-like domain resin, and a proteasomal chymotrypsin-like activity assay was performed. Proteasomal activity was significantly decreased in the brain tissue of Tg mice. C: Accumulation of polyubiquitinated proteins in Tg mice. Polyubiquitinated proteins were increased in the brains of Tg mice. D: Immunohistochemical staining for ubiquitin ( $\mathrm{Ub})$. Ub was slightly increased in the brain tissue of $\mathrm{Tg}$ mice. The 24-week-old WT and Tg mice were subjected to the experiments. Data are expressed as means \pm SD (B and $\mathbf{C}) . n=3$ mice per group $(\mathbf{A}) ; n=4$ mice per group $(\mathbf{B}) ; n=6$ mice per group $(\mathbf{C})$. ${ }^{\star} P<0.05$, $* * * P<0.001$ versus WT ( $t$-test). Scale bars $=50 \mu \mathrm{m}(\mathbf{D})$. 
the time spent in the open arms were comparable in WT and Tg mice (Figure 2B), indicating no difference in locomotor activity or anxiety-like behavior between the two types of mice. The pain response was also equivalent (Figure 2C). In the contextual fear conditioning test, WT and Tg mice demonstrated no difference in freezing behavior before being exposed to foot shocks. However, the total freezing time of Tg mice was significantly shorter than that of WT mice on day 0 during foot shocks, indicating that $\mathrm{Tg}$ mice had impaired memory acquisition (Figure 2D). The total freezing time after foot shocks was also decreased on days 1 and 2 in Tg mice compared with WT mice, suggesting that $\mathrm{Tg}$ mice may have had memory impairment that included memory retrieval. Taken together, $\mathrm{Tg}$ mice showed impaired acquisition of fear memory, which was not attributed to increased locomotor activity, attenuated anxiety, or decreased pain sensitivity.

\section{Decreased Proteasomal Function Accelerates Neuronal Loss in Vivo}

Because $\mathrm{Tg}$ mice exhibited memory impairment, we examined whether they also had neuronal loss. Brain sections from 24-week-old WT and Tg mice were analyzed using $\left[{ }^{125}\right.$ I]iomazenil autoradiography. Representative autoradiogram images are shown in Figure 3A. The levels of $\left[{ }^{125} I\right]$ iomazenil activity in regions of interest in brain areas, including the cortex and hippocampus, were analyzed; the relative intensity was decreased in regions of interest in Tg mice (Figure 3B). The ratio of hippocampal/ cortical $\left[{ }^{125}\right.$ I]iomazenil activity was significantly decreased in $\mathrm{Tg}$ mice, indicating that $\mathrm{Tg}$ mice exhibited hippocampal neuronal loss compared with WT mice. Next, brain sections from 4- and 24-week-old WT and Tg mice were analyzed to count the number of neuronal cells in the hippocampal CA1 region (Figure 3, C and D). In Tg mice, the number of neuronal cells was significantly decreased at 24 weeks of age, but was comparable to WT mice at 4 weeks of age. The number of neuronal cells was further decreased at 48 weeks of age, suggesting that aging was associated with neuronal cell death in the hippocampi of $\mathrm{Tg}$ mice (Supplemental Figure S2). A small number of terminal deoxynucleotidyl transferase-mediated dUTP nick-end labeling-positive cells was observed in the hippocampal CA1 region of $\mathrm{Tg}$ mice (Figure 3E). There were no detectable terminal deoxynucleotidyl transferase-mediated dUTP nickend labeling-positive cells in brain tissues of WT mice (data not shown). The protein levels of NGF in brain tissues of $\mathrm{Tg}$ mice were lower than those in WT mice, but there was no difference in NGF- $\beta$ mRNA expression (Figure 3, F and G).

\section{Decreased Proteasomal Function Promotes ER Stress-Mediated Apoptosis Pathways and Increased Hyperphosphorylation of Tau}

Proteasomal dysfunction alters proteostasis and induces the accumulation of unfolded proteins, which affects ER functions and leads to ER stress in neuronal cells. In patients with $\mathrm{AD}$, the accumulation of $\mathrm{p}$-tau was observed in neurons affected by ER stress. ${ }^{22}$ ER stress and hyperphosphorylation of tau protein were shown to induce each other and were both involved in the pathogenesis of neurodegeneration, including that occurring in
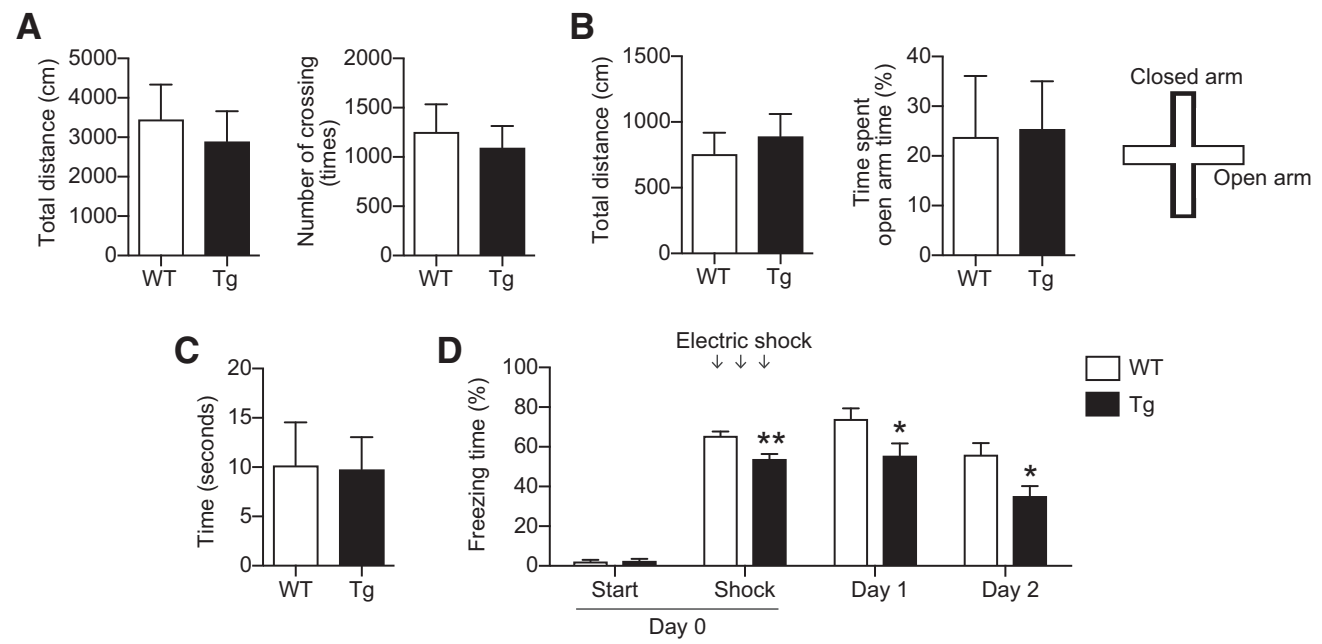

Figure 2 Decreased proteasomal function causes memory impairment in vivo. A: Open field test. Total distance traveled and total number of crosses across squares were analyzed. B: Elevated plus-maze test. The total distance traveled and the time spent in the open arms were analyzed. C: Hot-plate test. Mice were placed on a hot plate, and the latency for the animal to lick its hind paw or jump was measured to test pain response. D: Contextual fear conditioning test. After exposure to foot shocks, the freezing behavior in the absence of shocks was monitored to analyze fear memory retrieval. The 24-week-old wild-type (WT) and transgenic $(\mathrm{Tg})$ mice were subjected to the experiments. Data are expressed as means \pm SD (A-D). $n=12$ mice per group $(\mathbf{A}$ and $\mathbf{D}) ; n=7$ mice per group (B and $\mathbf{C}$ ). ${ }^{*} P<0.05,{ }^{*} P<<0.01$ versus WT (t-test). 
A
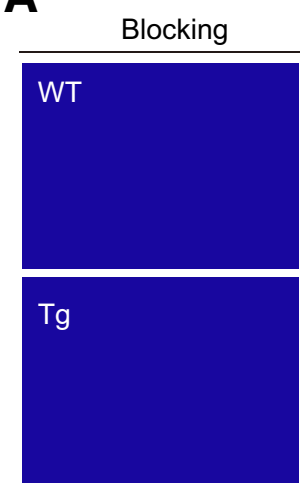

$\left[{ }^{125}\right.$ I]lomazenil
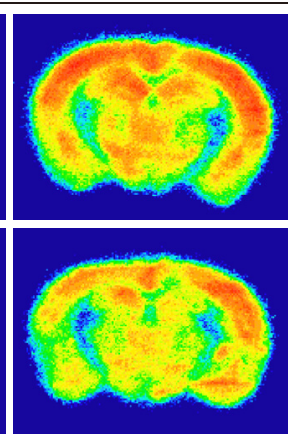

C

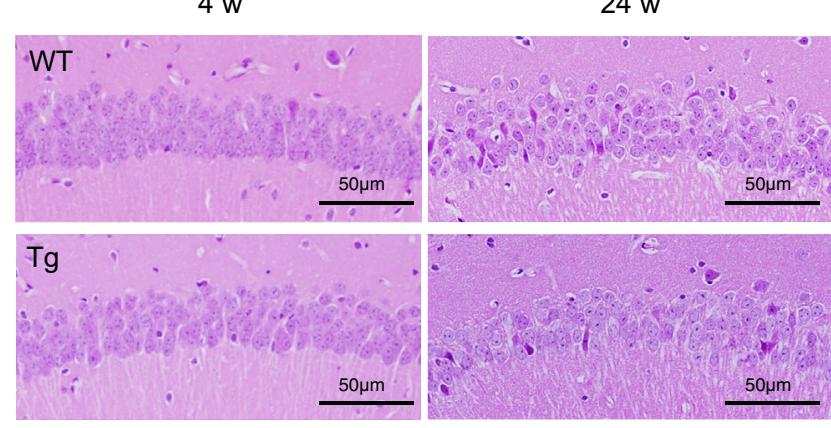

E

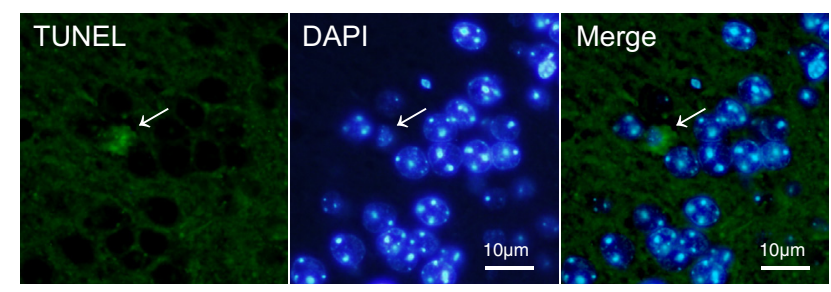

B

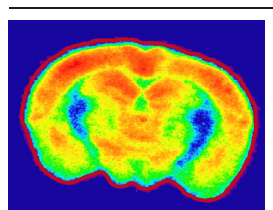

Whole

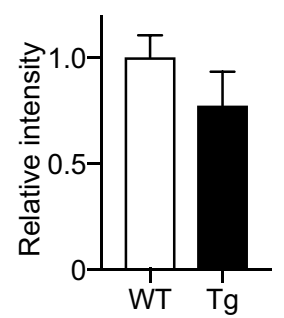

ROI

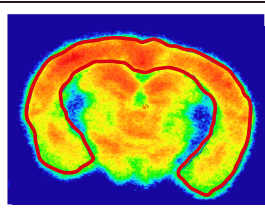

Cortex

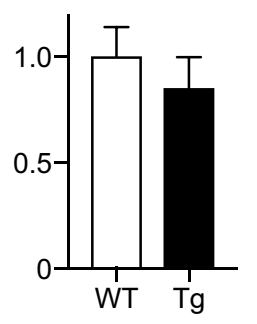

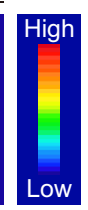

Hippocampus

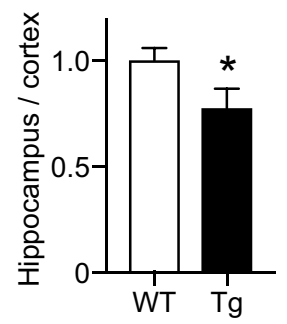

D



F

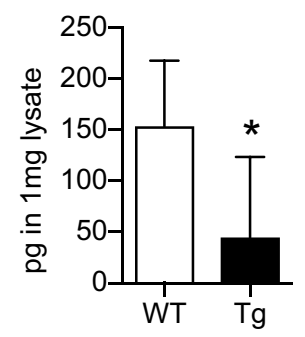

$24 w$

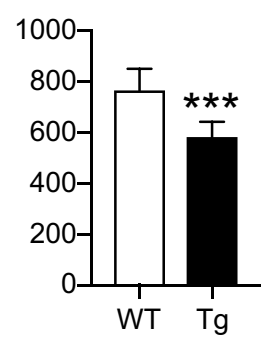

G

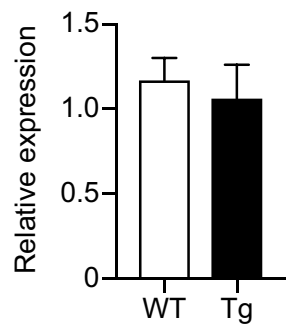

Figure 3 Decreased proteasomal function accelerates neuronal loss in vivo. A: Representative autoradiogram images of $\left[{ }^{125} \mathrm{I}\right]$ iomazenil autoradiography in wild-type (WT) and transgenic (Tg) mice at 24 weeks. The brain tissues were incubated with $\left[{ }^{125} \mathrm{I}\right]$ iomazenil and scanned. Following clonazepam preincubation, there was no non-specific binding of $\left[{ }^{125} \mathrm{I}\right]$ iomazenil. B: The intensity of $\left[{ }^{125} \mathrm{I}\right]$ iomazenil activity in the regions of interest (ROIs; whole brain, cortex, and hippocampus) was analyzed. Data were evaluated by relative values, setting the mean intensity of WT controls as 1 . C: Representative histologic images of the hippocampal CA1 region in WT and Tg mice at 4 and 24 weeks. D: The number of neuronal cells was counted per predetermined area in the hippocampal CA1 region. E: Representative histologic images of apoptotic cells in the hippocampal CA1 region of Tg mice. Terminal deoxynucleotidyl transferase-mediated dUTP nick-end labeling (TUNEL)-positive cells (white arrows) were observed. F: Nerve growth factor (NGF) in WT and Tg mice at 24 weeks. NGF in brain tissue lysates was measured by enzyme-linked immunosorbent assay. G: Expression of NGF- $\beta$ in WT and Tg mice at 24 weeks. Total RNA from brain tissue was subjected to quantitative PCR. Data are expressed as means \pm SD (B, D, F, and $\mathbf{G}) . n=3$ mice per group (B); $n=10$ mice per group (D and $\mathbf{F}) ; n=8$ mice per group (G). ${ }^{*} P<0.05,{ }^{* *} P<0.001$ versus WT (t-test). Scale bars: $50 \mu \mathrm{m}$ (C); $10 \mu \mathrm{m}(\mathbf{E})$.

AD. ${ }^{23}$ Although these observations suggest that proteasomal function and ER stress are likely to be linked in tau-related pathology, little is known of their direct relationship. It was therefore examined whether decreased proteasomal function induced the activation of ER stress-mediated apoptosis pathways and hyperphosphorylation of tau. In terms of the ER stress pathways, the expression levels of C/EBP homologous protein and phosphorylated JNK (the activated form of JNK) were higher in brain tissues of Tg mice than WT mice (Figure 4 and Supplemental Figure S3). Protein kinase-like endoplasmic reticulum kinase, a central ER 


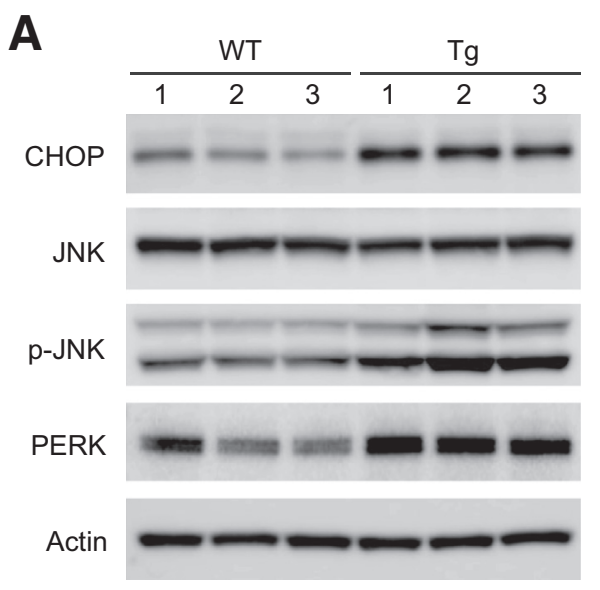

\section{B}
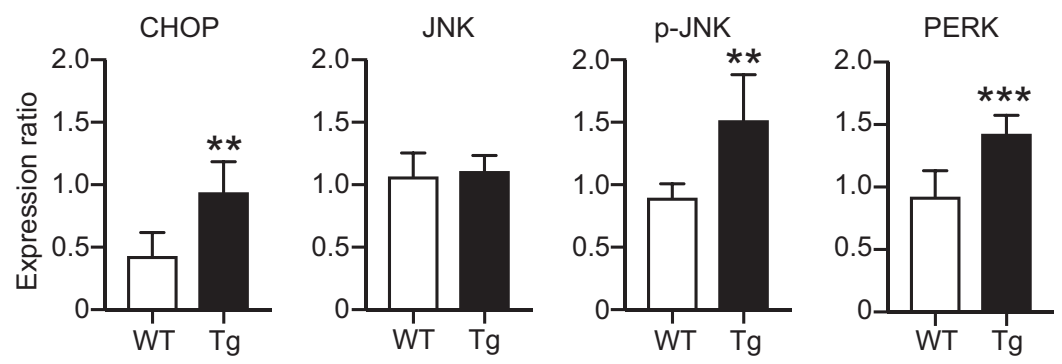

Figure 4 Decreased proteasomal function promotes the activation of the endoplasmic reticulum (ER) stress-mediated apoptosis pathway in vivo. Expression of proteins associated with ER stress-mediated molecules in the brains of wild-type (WT) and transgenic (Tg) mice. A: Immunoblotting is shown. B: The expression ratios of target proteins/actin were determined by image analysis of the Western blot data. Lanes 1, 2, and 3 represent individual mice, and the data for the other three mice are shown in Supplemental Figure S3. Data are expressed as means \pm SD $(\mathbf{B}) . n=6$ per group (B). **P $<0.01$, $* * * P<0.001$ versus WT ( $t$-test). CHOP, C/EBP homologous protein; JNK, c-Jun N-terminal kinase; PERK, protein kinase RNA-like ER kinase; $p$-JNK, phosphorylated JNK.

stress sensor, was also increased in the brain tissue of $\mathrm{Tg}$ mice, suggesting that chronic ER stress occurred in $\mathrm{Tg}$ mice. ${ }^{24}$ In addition, total tau and p-tau with phosphorylation at Ser396, the latter of which has been heavily implicated in $\mathrm{AD}$-associated tau pathology, ${ }^{25}$ were increased in $\mathrm{Tg}$ mice (Figure 5, $\mathrm{A}$ and $\mathrm{B}$, and Supplemental Figure S4A). These results suggest that ER stress-mediated apoptosis pathways are induced in neuronal cells in vivo under the condition of decreased proteasomal activity. Furthermore, immunohistochemical analysis indicates p-tau accumulation in hippocampal neuronal cells (Figure 5C).

The hyperphosphorylation of tau is regulated by several kinases, such as GSK-3 $\beta$, CDK5, and JNK. ${ }^{26,27}$ The enzymatic activity of CDK5 requires association with its regulatory activator, p35; in addition, p25, a calpain cleavage product of $\mathrm{p} 35$, causes prolonged activation of CDK5. ${ }^{28}$ The activation of JNK in the brains of $\mathrm{Tg}$ mice is already discussed above (Figure 4). However, activation of GSK-3 $\beta$ or CDK5 was not observed in Tg mice (Figure 5, D and E, and Supplemental Figure S4B), suggesting that JNK activation was involved in tau hyperphosphorylation. In contrast to the accumulation of total tau and p-tau, there was no increase in the level of $A \beta$ in $T g$ mice (Figure $5 \mathrm{~F}$ ). There were also no remarkable deposits of $A \beta$ in the brains of $T g$ mice (data not shown).

\section{Proteasomal Inhibition Induces the Activation of ER Stress-Mediated Apoptosis Pathways in Vitro}

For further confirmation of whether decreased proteasomal activity aggravates ER stress and neuronal death, in vitro experiments were performed using a murine hippocampal cell line, HT-22. HT-22 cells were incubated in medium containing MG-132 for 24 hours, and the activation of ER stress-mediated apoptosis pathways and the induction of cell death were examined. The expression levels of phosphorylated JNK increased remarkably in proportion to the dose of MG-132 (Figure 6A). Treatment with MG-132 increased the death rate of HT-22 cells, which was partially reversed by treatment with the JNK inhibitor SP600125, indicating that activation of the JNK pathway was involved in HT-22 cell death through proteasomal inhibition (Figure 6B). In HT-22 cells, treatment with MG132 affected the activation of kinases regulating tau phosphorylation: proteasomal inhibition increased the inactive form of GSK-3 $\beta$ (phosphorylated GSK-3 $\beta$ ) and decreased CDK5 and its regulatory activator, p35 (Figure 6C). Taken together, decreased proteasomal function induced the activation of ER stress-mediated apoptosis pathways and caused neuronal cell death in vitro, and among the analyzed kinases associated with tau phosphorylation, JNK was the only one that was up-regulated.

\section{Neuronal Cell Death in Vitro Is Increased Synergistically by Decreased Proteasomal Function and CSE-Induced Oxidative Stress}

Reactive oxygen species contribute to the onset of various disorders, including neurodegenerative diseases. ${ }^{29}$ The sources of reactive oxygen species can be endogenous or exogenous: inflammation, stress, infection, and agingrelated disruption of cellular metabolism are endogenous sources, whereas smoking, drinking, heavy metals, and radiation are canonical exogenous sources. Lifestyle-related sources of reactive oxygen species, such as smoking, increase the risk of $\mathrm{AD} .{ }^{30}$ We therefore examined whether neuronal cell death was increased synergistically by the 
A

p-tau

Actin

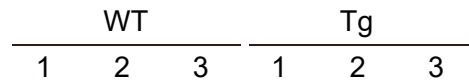

\section{(1)}
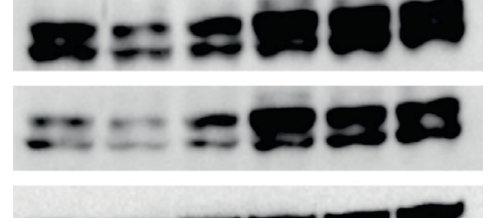

C

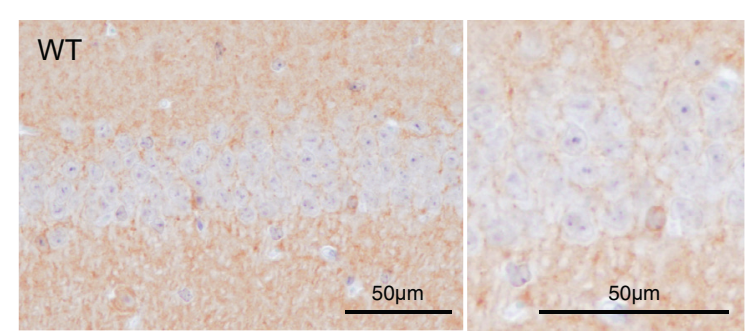

D

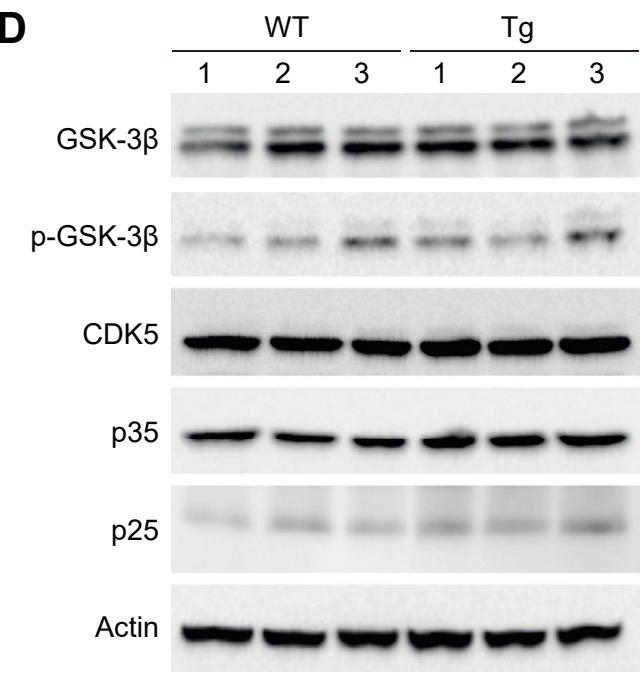

E
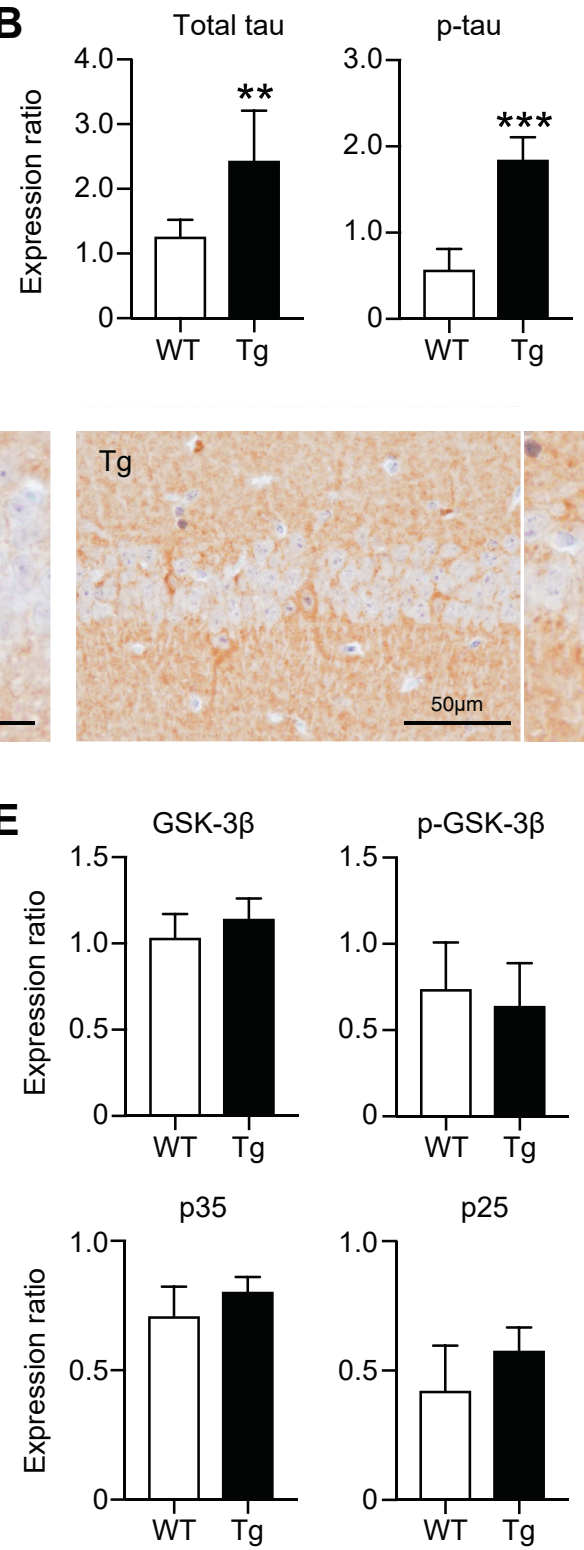

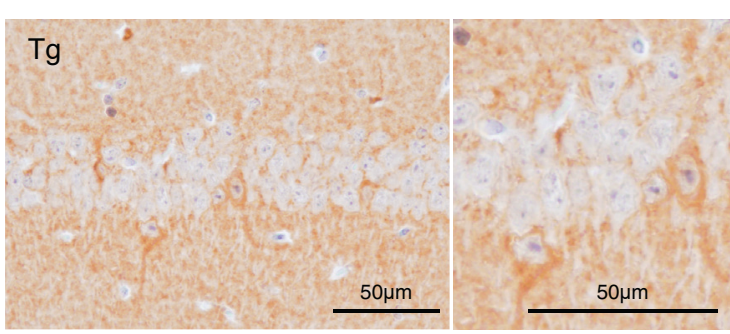

$\mathbf{F}$

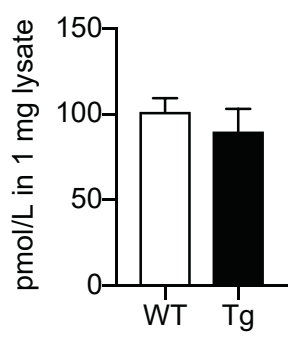

Figure 5 Decreased proteasomal function increases hyperphosphorylation of tau in vivo. A and B: Tau and phosphorylated tau (p-tau) proteins in the brains of wild-type (WT) and transgenic (Tg) mice. A: Immunoblotting is shown. B: The expression ratios of target proteins/actin were determined by image analysis of the Western blot data. C: Representative immunohistochemical staining for p-tau in the hippocampal CA1 region of 24-week-old WT and Tg mice. D and E: Expression of proteins associated with the phosphorylation of tau in the brains of WT and Tg mice. D: Immunoblotting is shown. E: The expression ratios of target proteins/actin were determined by image analysis of the Western blot data. Cyclin-dependent kinase 5 (CDK5) is activated in post-mitotic neurons via the neuron-specific activator p35. CDK5 is hyperactivated by p25, which is the N-terminal truncated form of p35. F: $\beta$-Amyloid (A $)$ in the brains of WT and Tg mice. $A \beta$ in brain tissue lysates was measured by enzyme-linked immunosorbent assay (ELISA). Extracts from brains of 24-week-old WT and Tg mice were applied for the immunoblotting and ELISA. Lanes 1, 2, and 3 represent individual mice (A and $\mathbf{D})$, and the data for the other three mice are shown in Supplemental Figure S4. Data are expressed as means \pm SD (B, E, and $\mathbf{F}) . n=6$ mice per group $(\mathbf{A}, \mathbf{B}, \mathbf{D}$, and $\mathbf{E}) ; n=8$ mice per group $(\mathbf{F})$. ${ }^{* *} P<0.01$,

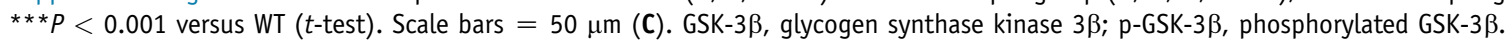


A

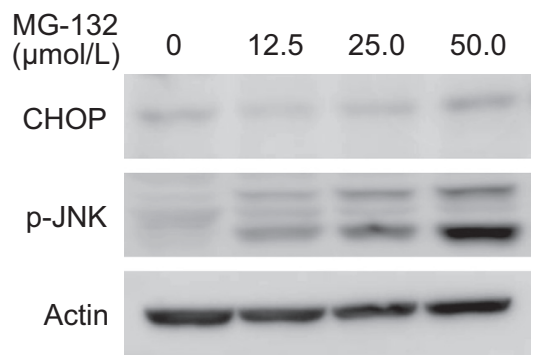

C



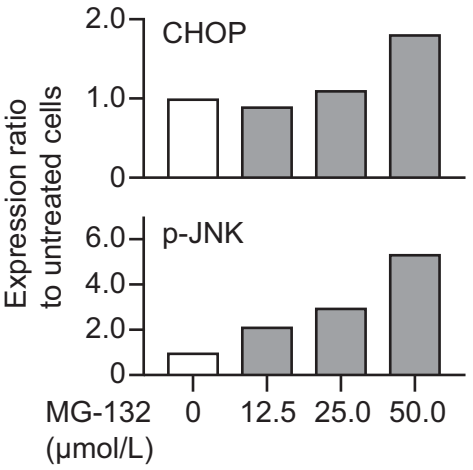

B

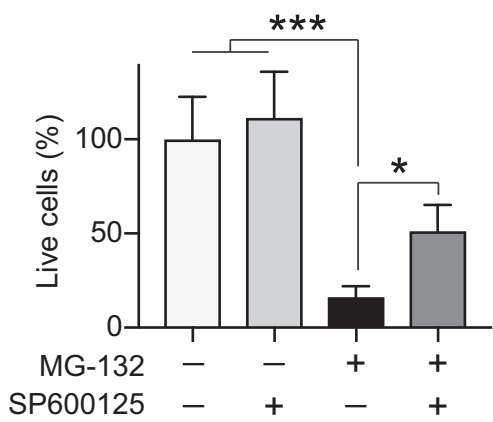

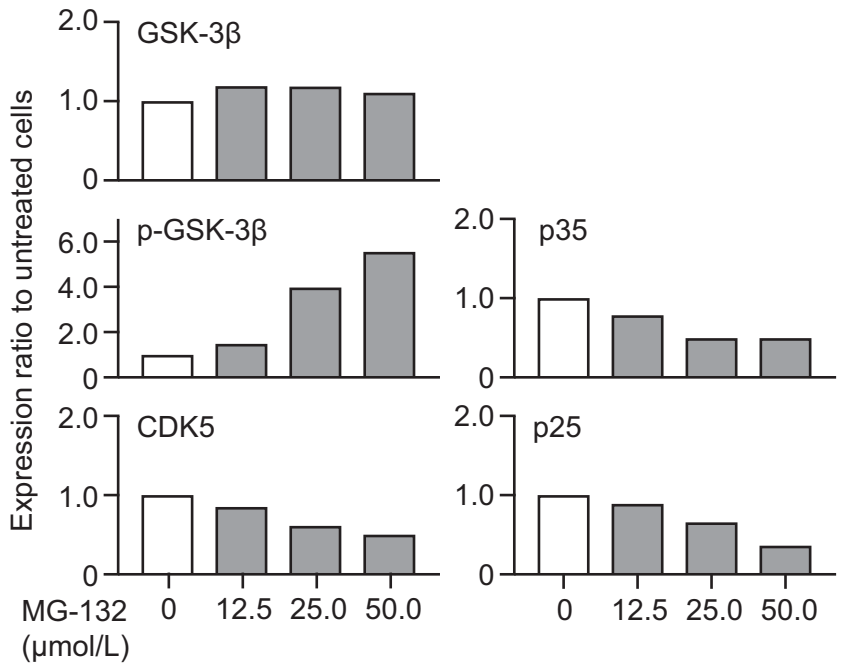

Figure 6 Proteasomal inhibition induces the activation of the endoplasmic reticulum stress-mediated apoptosis pathway in vitro. A: Expression of C/EBP homologous protein (CHOP) and phosphorylated c-Jun N-terminal kinase (p-JNK) in HT-22 cells following treatment with MG-132. HT-22 cells were incubated in culture medium containing the indicated concentrations of MG-132. Immunoblotting results are shown. The expression ratios of target proteins/actin were determined by image analysis of the Western blot data, and data were evaluated by relative values, setting the intensity of the untreated control to 1 . B: Cell death in HT-22 cells following treatment with MG-132. HT-22 cells were incubated in culture medium containing $50 \mu \mathrm{mol} / \mathrm{L}$ MG-132 and/or $100 \mathrm{nmol} / \mathrm{L}$ SP600125. C: Expression of proteins associated with tau phosphorylation. HT-22 cells were incubated in culture medium containing the indicated concentrations of MG-132. Immunoblotting results are shown. The expression ratios of target proteins/actin were determined by image analysis of the Western blot data, and data were evaluated by relative values, setting the intensity of the untreated control to 1 . Data are expressed as means \pm SD from three independent experiments (B). ${ }^{*} P<0.05,{ }^{*} * P<0.001$. CDK5, cyclin-dependent kinase 5; GSK-3 $\beta$, glycogen synthase kinase $3 \beta ; \mathrm{p}-\mathrm{GSK}-3 \beta$, phosphorylated GSK-3 $\beta$.

combination of decreased proteasomal function and reactive oxygen species induction by CSE, an in vitro model of lifestyle-related oxidative stress. HT-22 cells were incubated in CSE-containing medium for 24 hours with or without coincubation with MG-132. When HT-22 cells were treated with both CSE and MG-132, neuronal cell death was significantly increased in comparison with cells treated with MG-132 or CSE alone (Figure 7A). Similarly, the induction of phosphorylated JNK was greater in HT-22 cells treated with both CSE and MG-132 than in cells treated with MG132 or CSE alone (Figure 7B). Interestingly, when HT-22 cells were incubated with CSE, proteasomal activity was decreased, suggesting that oxidative stress affects proteasomal function (Figure 7C). Taken together, these results indicate that impaired proteasomal function potentiates neuronal cell death induced by oxidative stress, and oxidative stress reciprocally affects proteasomal function.

\section{Discussion}

The proteasome is an intracellular protease responsible for most intracellular protein degradation. ${ }^{31}$ In particular, the proteasome degrades most oxidized, aggregated, and misfolded proteins. ${ }^{6,7}$ In neurodegenerative disorders, proteasomal function was shown to be impaired in the substantia nigra in Parkinson disease ${ }^{32}$ and in the hippocampus and parahippocampal gyrus in $\mathrm{AD} .^{13}$ Therefore, the functional impairment of the proteasome is assumed to trigger neurodegenerative diseases; however, the evidence supporting 

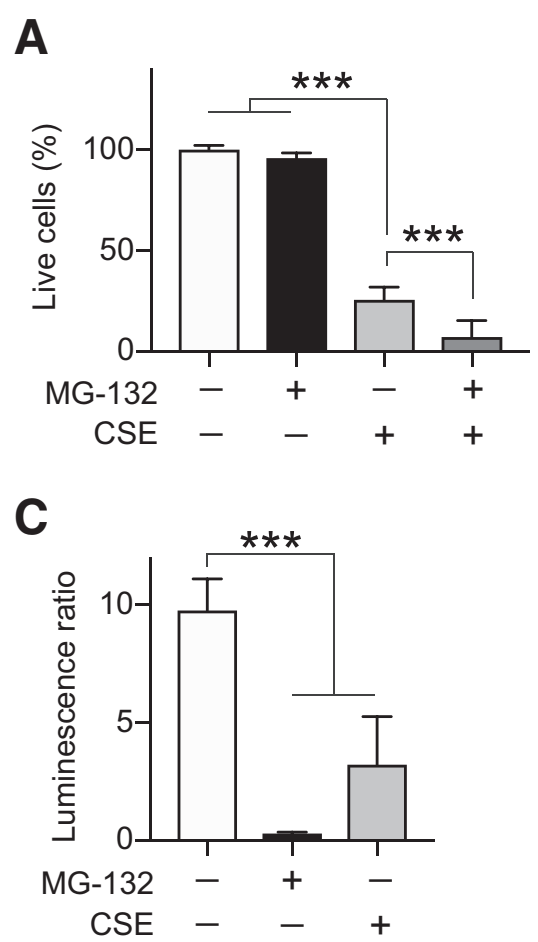

B

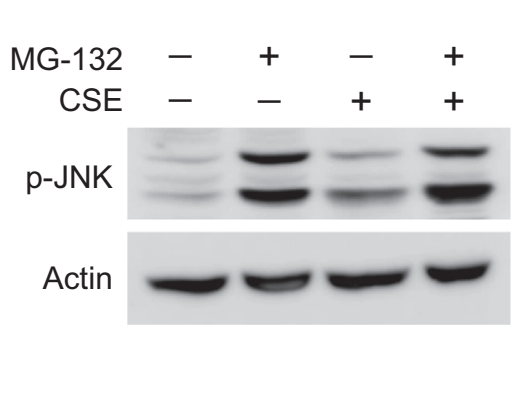

Figure 7 Decreased proteasomal function and cigarette smoke extract (CSE)-induced oxidative stress synergistically increase neuronal cell death in vitro. A: Cell death in HT-22 cells following treatment with $25 \mu \mathrm{mol} / \mathrm{L} \mathrm{MG}-132$ and/or 3.5\% CSE. B: Expression of phosphorylated c-Jun N-terminal kinase (p-JNK) following treatment with MG-132 and/or CSE. Immunoblotting results are shown. The expression ratios of target proteins/actin were determined by image analysis of the Western blot data, and data were evaluated by relative values, setting the intensity of the untreated control to 1 . C: Proteasomal activity in HT-22 cells following treatment with CSE. HT-22 cells were subjected to cell-based luminescence assays using a specific luminogenic proteasome substrate. Data are expressed as means $\pm S D$ from three independent experiments ( $\mathbf{A}$ and $\mathbf{C}) .{ }^{* *} P<0.001$.

this assumption has thus far been limited. In the present study, mice with reduced proteasomal activity showed memory impairment with neuronal loss. The brain tissue of $\mathrm{Tg}$ mice demonstrated up-regulation of ER stress-related apoptosis pathways and the hyperphosphorylation of tau in hippocampal neuronal cells. Thus, collective evidence suggests that impaired proteasomal activity induces altered proteostasis, and subsequent ER stress-mediated pathways play pivotal roles in neuronal loss.

Age-related decreases in proteasomal activity have been widely documented in many organs, including the brain, and these decreases are assumed to be involved in the aging process and the development of age-related pathologies. ${ }^{8,10,33}$ Sporadic AD (sAD) is the most common form of $\mathrm{AD}$, and its main risk factor is aging. ${ }^{34}$ Therefore, animal models that accelerate age-related physiological pathology may play a fundamental role in $\mathrm{AD}$ research. In this respect, mice with decreased proteasomal activity could serve as an ideal model for sAD with age-associated pathology. The present mouse model showed that the decline of proteasomal activity caused abnormal proteostasis that led to both ER stress and the hyperphosphorylation of tau. A striking finding in this model was the increase of tau and p-tau. The clearance of tau protein depends mainly on the ubiquitinproteasome system ${ }^{35}$; therefore, increased tau in the brain tissue of Tg mice could be simply explained by decreased proteasomal activity. In terms of the increase of p-tau, the expression of several major kinases associated with tau hyperphosphorylation was analyzed, and only the JNK pathway was significantly activated.
JNK is a component of an ER stress-mediated apoptosis pathway and plays a critical role in the formation of NFTs by direct phosphorylation of tau. ${ }^{36}$ Further studies analyzing other pathways, such as oxidative stress, the mitochondrial stress response, and autophagic flux, are necessary to dissect the molecular mechanisms of the increase of p-tau. The fundamental pathology in the present model is proteasomal dysfunction, and the impairment of the proteasome causes altered proteostasis and ER stress, which are common features of many neurodegenerative diseases. ${ }^{2,5}$ Therefore, the linkage between the decline of proteasomal function, the activation of ER stress, and the increased hyperphosphorylation of tau may be a notable pathologic process underlying neuronal loss in the present model. Interestingly, it has been reported that the proteasomal dysfunction in the brains of patients with $\mathrm{AD}$ is caused by the inhibitory binding of p-tau to proteasomes. ${ }^{37}$ Myeku et $\mathrm{al}^{38}$ demonstrated that the accumulation of insoluble tau was associated with a decrease in the peptidase activity of $26 \mathrm{~S}$ proteasomes in the brain. Taken together, an age-related reduction of proteasomal activity may cause a cycle in neurodegenerative diseases of decreased proteasomal activity directly causing ER stress-mediated neuronal loss and phosphorylation of tau, and the accumulation of p-tau leading to further inhibition of the ubiquitin-proteasome system. Moreover, several lifestyle habits that cause increased oxidative stress, such as smoking and a high-fat diet, are known to be risk factors for the development of $\mathrm{AD},{ }^{39,40}$ and may prolong the cycle of decreased proteasomal activity, ER stress, and neuronal death. 
Remarkably, the brain tissue of Tg mice showed accumulation of p-tau, but no amyloid deposition or NFTs. This is likely due to differences in protein characteristics between mice and humans. For example, C57BL/6 mice produce much lower numbers of the cleaved amyloid precursor protein fragments that are most prominent in humans. ${ }^{41}$ Mouse wild-type tau does not aggregate into NFTs, because it shares only $88 \%$ sequence homology with human tau. In contrast, NFTs readily form in transgenic mice expressing human tau that contains gene mutations associated with frontotemporal lobar degeneration: the most commonly used models are those that express $4 \mathrm{R}$ tau with P301L or P301S mutations. ${ }^{42,43}$ The vast majority of experimental models of $\mathrm{AD}$ involve transgenic mice expressing human proteins (such as amyloid precursor protein, presenilin 1, and tau) that result in the formation of amyloid plaques and NFTs ${ }^{43,44}$; however, the pathologic development in these models is non-physiological. AD is a uniquely human disease, and various models with neuropathologic features similar to those seen in AD should be examined on the basis of their protein biology. New animal models are expected to increasingly mimic SAD in terms of physiological alterations in proteostasis, and our model may serve as an appropriate foundation in this regard.

In $\mathrm{Tg}$ mice, neuronal loss occurred gradually after several months, and a small number of apoptotic cells were observed in the hippocampal CA1 region. In brain tissues of patients with $\mathrm{AD}$, no global neocortical nerve cell loss was found. ${ }^{45}$ Rather, AD-related neuronal loss occurred most prominently in the hippocampus. ${ }^{46}$ West et $\mathrm{al}^{46}$ reported that neuronal loss was seen in the CA1 region of the hippocampi of patients with $\mathrm{AD}$, but not in those of a healthy elderly group. Apoptotic cell death is a quick process, and is therefore sometimes difficult to detect in slowly progressive diseases. The lifespan of mice is different from that of humans. Although it is difficult to directly compare aging in mice and humans, sporadic apoptotic cell death may occur in the hippocampi of $\mathrm{Tg}$ mice as well as those of patients with $\mathrm{AD}$. This sporadic neuronal death in $\mathrm{Tg}$ mouse model may at least partly reflect the pathogenesis of human AD.

The mechanism underlying the age-related decline in proteasomal activity is not fully understood. Interestingly, it is not a general aging phenomenon, because particular cell types and tissues are more vulnerable than others. ${ }^{33}$ In rodent neuronal tissues, decreases in proteasomal chymotrypsin-like activity are evident in the cortex, hippocampus, and spinal cord, but not in the brain stem or cerebellum. ${ }^{47}$ Several types of alterations, including a decrease in proteasome subunits, altered subunit structure, post-translational modification of the proteasome, and impaired proteasome assembly, may be involved in the decrease in proteasomal function. ${ }^{33,48,49}$ It appears that proteasome activation may have a beneficial effect in the prevention and treatment of neurodegenerative diseases. It has been reported that direct cellular delivery of proteasomes can delay the aggregation of tau protein. ${ }^{50}$ However, this issue is still being investigated, and there is insufficient information on the adverse effects of drugs that effectively activate proteasomes. Because decreased proteasome function impairs the cellular response to stress, drugs that prevent stress-induced neuronal death may be useful. In the present study, the JNK inhibitor SP600125 prevented the death of HT-22 cells caused by proteasomal inhibition, suggesting that JNK activation is a key pathway responsible for neuronal death. Alterations of the JNK pathway are potentially associated with pathogenesis and neuronal death in $\mathrm{AD} .^{51}$ Therefore, drugs capable of inhibiting the JNK pathway are an attractive therapeutic strategy. Recently, both the pharmaceutical industry and academia have devoted considerable effort to investigating such drugs; however, it is not yet possible to directly inhibit JNK isoforms in specific tissues. Newer compounds, including kinase inhibitors and peptide inhibitors that bind to the JNK binding domain, are being developed with increasing specificity for JNK inhibition. $^{51,52}$

In conclusion, the $\mathrm{Tg}$ model described herein demonstrates the direct significance of in vivo proteasomal activity in the initiation and progression of neurodegenerative diseases. Our results suggest that the age-related decline in proteasomal activity plays a vital role in the accumulation of p-tau and neuronal loss. Future studies are needed to address the molecular mechanisms underlying proteasomal impairment with age, and to identify specific substrate proteins whose altered expression contributes to the development of neurodegenerative diseases. Such studies may provide a new approach to the prevention and treatment of sAD, the most common form of dementia worldwide.

\section{Acknowledgments}

We thank Dr. David Schubert for providing the HT-22 cell line; Kayo Miyazaki (Faculty of Medicine and Graduate School of Medicine, Hokkaido University) for technical support; and the staff of the Institute for Animal Experimentation (Faculty of Medicine and Graduate School of Medicine, Hokkaido University) for maintaining of the mice used in this study.

\section{Author Contributions}

U.T. conceived the project, performed in vitro experiments, and wrote the manuscript; T.I., Y.O., and S.M. performed in vivo experiments; U.T., R.T., T.H., and A.I. performed molecular biology experiments; U.T., T.I., K.H., A.I., and Y.K. performed histologic and imaging analysis; M.Y. and M.K. contributed ideas and supported the work.

\section{Supplemental Data}

Supplemental material for this article can be found at http://doi.org/10.1016/j.ajpath.2020.10.004. 


\section{References}

1. Soto C: Unfolding the role of protein misfolding in neurodegenerative diseases. Nat Rev Neurosci 2003, 4:49-60

2. Kaushik S, Cuervo AM: Proteostasis and aging. Nat Med 2015, 21: 1406-1415

3. Smith MH, Ploegh HL, Weissman JS: Road to ruin: targeting proteins for degradation in the endoplasmic reticulum. Science 2011, 334: $1086-1090$

4. Walter P, Ron D: The unfolded protein response: from stress pathway to homeostatic regulation. Science 2011, 334:1081-1086

5. Gerakis Y, Hetz C: Emerging roles of ER stress in the etiology and pathogenesis of Alzheimer's disease. FEBS J 2018, 285:995-1011

6. Poppek D, Grune T: Proteasomal defense of oxidative protein modifications. Antioxid Redox Signal 2006, 8:173-184

7. Amm I, Sommer T, Wolf DH: Protein quality control and elimination of protein waste: the role of the ubiquitin-proteasome system. Biochim Biophys Acta 2014, 1843:182-196

8. Chondrogianni N, Gonos ES: Proteasome dysfunction in mammalian aging: steps and factors involved. Exp Gerontol 2005, 40:931-938

9. Tonoki A, Kuranaga E, Tomioka T, Hamazaki J, Murata S, Tanaka K, Miura M: Genetic evidence linking age-dependent attenuation of the $26 \mathrm{~S}$ proteasome with the aging process. Mol Cell Biol 2009, 29:1095-1106

10. Lopez-Otin C, Blasco MA, Partridge L, Serrano M, Kroemer G: The hallmarks of aging. Cell 2013, 153:1194-1217

11. Dahlmann B: Role of proteasomes in disease. BMC Biochem 2007, 8(Suppl 1):S3

12. Ciechanover A, Brundin P: The ubiquitin proteasome system in neurodegenerative diseases: sometimes the chicken, sometimes the egg. Neuron 2003, 40:427-446

13. Keller JN, Hanni KB, Markesbery WR: Impaired proteasome function in Alzheimer's disease. J Neurochem 2000, 75:436-439

14. McNaught KS, Olanow $\mathrm{CW}$, Halliwell $\mathrm{B}$, Isacson $\mathrm{O}$, Jenner $\mathrm{P}$ : Failure of the ubiquitin-proteasome system in Parkinson's disease. Nat Rev Neurosci 2001, 2:589-594

15. Tomaru U, Takahashi S, Ishizu A, Miyatake Y, Gohda A, Suzuki S, Ono A, Ohara J, Baba T, Murata S, Tanaka K, Kasahara M: Decreased proteasomal activity causes age-related phenotypes and promotes the development of metabolic abnormalities. Am J Pathol 2012, 180:963-972

16. Ando R, Noda K, Tomaru U, Kamoshita M, Ozawa Y, Notomi S, Hisatomi T, Noda M, Kanda A, Ishibashi T, Kasahara M, Ishida S: Decreased proteasomal activity causes photoreceptor degeneration in mice. Invest Ophthalmol Vis Sci 2014, 55:4682-4690

17. Yamada Y, Tomaru U, Ishizu A, Ito T, Kiuchi T, Ono A, Miyajima S, Nagai K, Higashi T, Matsuno Y, Dosaka-Akita H, Nishimura M, Miwa S, Kasahara M: Decreased proteasomal function accelerates cigarette smoke-induced pulmonary emphysema in mice. Lab Invest 2015, 95:625-634

18. Ohmura Y, Tanaka KF, Tsunematsu T, Yamanaka A, Yoshioka M: Optogenetic activation of serotonergic neurons enhances anxiety-like behaviour in mice. Int $\mathrm{J}$ Neuropsychopharmacol 2014, 17: $1777-1783$

19. Committee for the Update of the Guide for the Care and Use of Laboratory Animals: National Research Council: Guide for the Care and Use of Laboratory Animals: Eighth Edition. Washington, DC, National Academies Press, 2011

20. Asano H, Horinouchi T, Mai Y, Sawada O, Fujii S, Nishiya T, Minami M, Katayama T, Iwanaga T, Terada K, Miwa S: Nicotineand tar-free cigarette smoke induces cell damage through reactive oxygen species newly generated by PKC-dependent activation of NADPH oxidase. J Pharmacol Sci 2012, 118:275-287

21. Murata S, Sasaki K, Kishimoto T, Niwa S, Hayashi H, Takahama Y, Tanaka K: Regulation of $\mathrm{CD}^{+} \mathrm{T}$ cell development by thymusspecific proteasomes. Science 2007, 316:1349-1353
22. Hoozemans JJ, van Haastert ES, Nijholt DA, Rozemuller AJ, Eikelenboom P, Scheper W: The unfolded protein response is activated in pretangle neurons in Alzheimer's disease hippocampus. Am J Pathol 2009, 174:1241-1251

23. Ho YS, Yang X, Lau JC, Hung CH, Wuwongse S, Zhang Q, Wang J, Baum L, So KF, Chang RC: Endoplasmic reticulum stress induces tau pathology and forms a vicious cycle: implication in Alzheimer's disease pathogenesis. J Alzheimers Dis 2012, 28:839-854

24. Foster AJ, Platt MJ, Huber JS, Eadie AL, Arkell AM, Romanova N, Wright DC, Gillis TE, Murrant CL, Brunt KR, Simpson JA: Centralacting therapeutics alleviate respiratory weakness caused by heart failure-induced ventilatory overdrive. Sci Transl Med 2017, 9: eaag 1303

25. Bramblett GT, Goedert M, Jakes R, Merrick SE, Trojanowski JQ, Lee VM: Abnormal tau phosphorylation at Ser396 in Alzheimer's disease recapitulates development and contributes to reduced microtubule binding. Neuron 1993, 10:1089-1099

26. Ferrer I, Gomez-Isla T, Puig B, Freixes M, Ribe E, Dalfo E, Avila J: Current advances on different kinases involved in tau phosphorylation, and implications in Alzheimer's disease and tauopathies. Curr Alzheimer Res 2005, 2:3-18

27. Churcher I: Tau therapeutic strategies for the treatment of Alzheimer's disease. Curr Top Med Chem 2006, 6:579-595

28. Tseng HC, Zhou Y, Shen Y, Tsai LH: A survey of Cdk5 activator p35 and p25 levels in Alzheimer's disease brains. FEBS Lett 2002, 523: $58-62$

29. Finkel T, Holbrook NJ: Oxidants, oxidative stress and the biology of ageing. Nature 2000, 408:239-247

30. Nunomura A, Castellani RJ, Zhu X, Moreira PI, Perry G, Smith MA: Involvement of oxidative stress in Alzheimer disease. J Neuropathol Exp Neurol 2006, 65:631-641

31. Coux O, Tanaka K, Goldberg AL: Structure and functions of the $20 \mathrm{~S}$ and 26S proteasomes. Annu Rev Biochem 1996, 65:801-847

32. McNaught KS, Jenner P: Proteasomal function is impaired in substantia nigra in Parkinson's disease. Neurosci Lett 2001, 297: 191-194

33. Keller JN, Gee J, Ding Q: The proteasome in brain aging. Ageing Res Rev 2002, 1:279-293

34. Selkoe DJ: Alzheimer's disease: genes, proteins, and therapy. Physiol Rev 2001, 81:741-766

35. Wang Y, Mandelkow E: Degradation of tau protein by autophagy and proteasomal pathways. Biochem Soc Trans 2012, 40:644-652

36. Lagalwar S, Guillozet-Bongaarts AL, Berry RW, Binder LI: Formation of phospho-SAPK/JNK granules in the hippocampus is an early event in Alzheimer disease. J Neuropathol Exp Neurol 2006, 65: 455-464

37. Tai HC, Serrano-Pozo A, Hashimoto T, Frosch MP, Spires-Jones TL, Hyman BT: The synaptic accumulation of hyperphosphorylated tau oligomers in Alzheimer disease is associated with dysfunction of the ubiquitin-proteasome system. Am J Pathol 2012, 181:1426-1435

38. Myeku N, Clelland CL, Emrani S, Kukushkin NV, Yu WH, Goldberg AL, Duff KE: Tau-driven 26S proteasome impairment and cognitive dysfunction can be prevented early in disease by activating cAMP-PKA signaling. Nat Med 2016, 22:46-53

39. Durazzo TC, Mattsson N, Weiner MW: Alzheimer's Disease Neuroimaging Initiative: Smoking and increased Alzheimer's disease risk: a review of potential mechanisms. Alzheimers Dement 2014, 10: S122-S145

40. Edwards GA III, Gamez N, Escobedo G Jr, Calderon O, MorenoGonzalez I: Modifiable risk factors for Alzheimer's disease. Front Aging Neurosci 2019, 11:146

41. Hunter JM, Bowers WJ, Maarouf CL, Mastrangelo MA, Daugs ID, Kokjohn TA, Kalback WM, Luehrs DC, Valla J, Beach TG, Roher AE: Biochemical and morphological characterization of the $\mathrm{A} \beta \mathrm{PP} / \mathrm{PS} /$ tau triple transgenic mouse model and its relevance to sporadic Alzheimer's disease. J Alzheimers Dis 2011, 27:361-376 
42. Gotz J, Ittner LM: Animal models of Alzheimer's disease and frontotemporal dementia. Nat Rev Neurosci 2008, 9:532-544

43. Drummond E, Wisniewski T: Alzheimer's disease: experimental models and reality. Acta Neuropathol 2017, 133:155-175

44. Sasaguri H, Nilsson $P$, Hashimoto $S$, Nagata K, Saito T, De Strooper B, Hardy J, Vassar R, Winblad B, Saido TC: APP mouse models for Alzheimer's disease preclinical studies. EMBO J 2017, 36:2473-2487

45. Regeur L, Jensen GB, Pakkenberg H, Evans SM, Pakkenberg B: No global neocortical nerve cell loss in brains from patients with senile dementia of Alzheimer's type. Neurobiol Aging 1994, 15: 347-352

46. West MJ, Coleman PD, Flood DG, Troncoso JC: Differences in the pattern of hippocampal neuronal loss in normal ageing and Alzheimer's disease. Lancet 1994, 344:769-772

47. Keller JN, Hanni KB, Markesbery WR: Possible involvement of proteasome inhibition in aging: implications for oxidative stress. Mech Ageing Dev 2000, 113:61-70
48. Carrard G, Bulteau AL, Petropoulos I, Friguet B: Impairment of proteasome structure and function in aging. Int J Biochem Cell Biol 2002, 34:1461-1474

49. Mao L, Romer I, Nebrich G, Klein O, Koppelstatter A, Hin SC, Hartl D, Zabel C: Aging in mouse brain is a cell/tissue-level phenomenon exacerbated by proteasome loss. J Proteome Res 2010, 9: $3551-3560$

50. Han DH, Na HK, Choi WH, Lee JH, Kim YK, Won C, Lee SH, Kim KP, Kuret J, Min DH, Lee MJ: Direct cellular delivery of human proteasomes to delay tau aggregation. Nat Commun 2014, 5:5633

51. Yarza R, Vela S, Solas M, Ramirez MJ: c-Jun N-terminal kinase (JNK) signaling as a therapeutic target for Alzheimer's disease. Front Pharmacol 2015, 6:321

52. Uitdehaag JC, Verkaar F, Alwan H, de Man J, Buijsman RC, Zaman GJ: A guide to picking the most selective kinase inhibitor tool compounds for pharmacological validation of drug targets. $\mathrm{Br} \mathrm{J}$ Pharmacol 2012, 166:858-876 